\title{
"Eu desisto?"1 Paredes vivas na cidade: conflitos sociais em cartazes produzidos ao longo da década de 1980, no Brasil ${ }^{2}$
}

\section{"Do I give up?" Live walls in the city: social conflicts in posters produced during the 80 s in Brazil}

\author{
Marcus Aurelio Taborda de Oliveira ${ }^{3}$
}

\begin{abstract}
RESUMO
O trabalho foca um conjunto de cartazes produzido com o fito de mobilizar a sociedade brasileira em prol de demandas sufocadas durante o período ditatorial, que não foi um epifenômeno de uma tradição de recorrente violência. Com a reorganização da sociedade civil ao longo da década de 1980, a chamada década perdida, diferentes agentes coletivos se mobilizaram para dar visibilidade aos seus anseios. Privilegiando a imagem expressa em cartazes, a propaganda destes grupos e, em alguns casos, mesmo do Estado, buscava destacar o advento de um novo tempo, no qual antigas e novas reivindicações poderiam ser finalmente contempladas, desde que a população se organizasse para tal fim. Para além do panfleto político escrito e direto, os cartazes representaram na história uma possibilidade de captar o observador pela imagem, pela cor, pelo traço que, às vezes combinados com o texto, desenvolveriam sua sensibilidade para uma problemática específica.
\end{abstract}

1 Algumas pessoas muito queridas e de rara sensibilidade contribuíram com uma leitura cuidadosa do original que deu origem a este artigo: Katya Braghini, Suzete Bornatto, Alexandre Fernandez Vaz e Fernanda Cristina Campos da Rocha. Nenhuma delas é responsável pelo que vai aqui apresentado. A elas, especialmente Fernanda e Alexandre, dedico este trabalho. Eles bem sabem por quê.

2 O trabalho é parte dos resultados do projeto A educação dos sentidos na história: o tempo livre como possibilidade de formação (entre os anos finais do séc. XIX e os anos iniciais do séc. XXI), desenvolvido junto ao NUPES - Núcleo de Pesquisas sobre a Educação dos Sentidos e das Sensibilidades, da Universidade Federal de Minas Gerais/Brasil, com financiamento do CNPq sob n. 470687/2011-8, da CAPES, sob n. AUX-PE-PNPD 2587/2011 e da FAPEMIG, sob n. APQ 00635/11.

3 Universidade Federal de Minas Gerais. Belo Horizonte, Minas Gerais, Brasil. Av. Antonio Carlos, 6227, Campus Pampulha. CEP: 30535-470. 
Muitas daquelas reivindicações que compuseram a agenda política do fim da ditadura e dos primeiros anos da volta à democracia, ainda hoje, quase 40 anos depois, continuam a ser objeto da mobilização popular. Isso atesta o quanto, a despeito dos horrores promovidos pela ditadura civil-militar que pontificou neste país entre 1964 e 1985, elites, governos e parcelas da sociedade brasileira relutam em resolver questões tão prementes quanto básicas, tais como a reforma agrária, a violência contra as minorias, a perversa concentração de renda, o corporativismo, a corrupção entre tantas outras mazelas. Assim, procurando fazer dialogar texto e imagem, passado e presente, o trabalho recupera a pergunta feita pela Graúna, de Henfil: haveria alguma esperança?

Palavras-chave: ditadura militar; sociedade civil; lutas populares; educação das sensibilidades.

\begin{abstract}
This article intends to analyze some posters produced which intended to mobilize Brazilian society in favour of repressed demands during the dictatorial period which was not a detail in the large tradition of violence. Since the reorganization of the civil society in the $80 \mathrm{~s}$, called the lost decade, different collective agents mobilized themselves to give visibility to their desires. Privileging the image in posters, the propaganda of these groups and, in some cases, even the State image, they tried to highlight the beginning of a new era, in which past and new claims could be finally contemplated, if people organized themselves for this end. Beyond a written and direct political pamphlet, the posters represented in History a possibility to catch the observer through an image, color, and the trace that, sometimes combined with the text, would develop one's sensibility for a specific problem. A lot of the demands that composed the political plans in the end of the Brazilian dictatorship, and in the first years of the re-democratization until today, almost 40 years later, they are still objects of popular mobilization. This fact attests how much, independently of the horror promoted by civil-military dictatorship in Brazil between 1964 and 1985, elites, government and parts of the Brazilian population are still reluctant to solve important and basic questions, such as the land reform, violence against minorities, the perverse income concentration, corporatism, corruption, among many others. So, through a dialogue between text and image, past and present, this work asks the Grauna`s question, by Henfil: should we have any hope?
\end{abstract}

Keywords: military dictatorship; civil society; popular struggles; education of sensibilities. 
Em 1970 Taiguara lançava o LP Viagem, seu sétimo, que tinha como primeira canção Universo no teu corpo. Sua letra, que seria consagrada, anunciava: "Eu desisto, não existe essa manhã que eu perseguia, um lugar que me dê trégua ou me sorria, uma gente que não viva só pra si”. Eram os anos de chumbo, e muitos registros culturais mostram uma oscilação entre o desencanto e a militância. Em 1983, em um espetáculo ao vivo no Teatro Guaíra, em Curitiba, o compositor se declarava confiante na derrocada final da ditadura e atualizava a letra da sua canção, cantando: "Eu resisto! Sim, existe essa manhã que eu perseguia...". Não apenas pelo fato de ter sido um dos artistas mais visados pela ditadura, mas, sobretudo, por ter tomado posições muito claras contra o arbítrio e o autoritarismo daqueles quase 20 anos de regime autoritário, a mudança de ânimo deste artista é o meu ponto de partida para discutir, analisando mensagens expressas em um tipo pouco usual de fonte histórica, os cartazes, a tentativa da sociedade brasileira se reorganizar a partir de diferentes expressões culturais nos anos finais da ditadura e nos primeiros anos após o seu término.

Embora um tipo de canção, denominada "de protesto", tenha marcado parte da produção cultural do período, a obra de Taiguara é portadora de grande beleza e refinamento, não se prestando ao panfleto político, como aquele marcado pelas canções ufanistas do período, ou pelas canções de denúncia e resistência de qualidade mais do que duvidosa. A partir de composições complexas, refinadas e letras de grande lirismo, o autor dava mostras que a política não precisa abrir mão da qualidade estética, inclusive como valorização das inúmeras possibilidades de expressão do "povo". Sua obra, entendo, não se presta a nenhum tipo de populismo cultural.

Os anos que enfeixam o fim da ditadura brasileira até os primeiros anos do retorno à democracia já foram caracterizados por muitos, sobretudo economistas, como representativos de uma década perdida. Mas foi um momento da história brasileira no qual muito do que havia sido violentamente reprimido voltava à cena pública revigorado, atualizando um conjunto de práticas de resistência que marcaram a trajetória de lutas dos movimentos sociais brasileiros, que contribuíram para que a memória histórica fosse constantemente atualizada, combatendo as tentativas de apaziguamento ou esquecimento patrocinadas pelos grupos política e economicamente dominantes.

Com o esgarçar-se da censura e da repressão, um sem número de manifestações ganhou ruas, praças, avenidas com a presença maciça daqueles que ainda acreditavam que o sonho não havia acabado. Mas também uma dimensão fortemente imagética ajudou a atualizar as possibilidades de reorganização da sociedade civil: a propaganda por meio de cartazes que eram fixados em universidades, pontos de ônibus, igrejas, centros culturais etc. Talvez no que tenha sido o último suspiro desse tipo de propaganda, no Brasil, uma vez que a 
rede mundial de computadores reduziria nos cartazes sua eficácia comunicativa, muito se produziu como propaganda direta naquele formato ${ }^{4}$. Vindo do próprio Estado que se reorganizava, de partidos que surgiam ou se reestruturavam, de movimentos sociais, sindicatos, organismos variados da sociedade civil, o cartaz dava visibilidade a novas e antigas lutas, sufocadas pelos anos de arbítrio, mas que podiam novamente ganhar as ruas. Documentos como esses fazem parte da memória que atesta a complexidade da sociedade, a pluralidade dos seus interesses, desafios e lutas, a diferença na posse de recursos para divulgar as possibilidades de soerguimento de uma sociedade combalida pela violência, pelo medo, pela desesperança que são alguns dos seus traços historicamente mais evidentes.

John Berger (2012), crítico contumaz da propaganda reduzida à publicidade, a entende como a forma acabada de dominação nas sociedades capitalistas, uma vez que ela levaria às últimas consequências a reificação, a perda da alteridade, o esfacelamento da cultura comum, compartilhada.

A publicidade constitui uma espécie de sistema filosófico. Explica a tudo nos seus próprios termos. Interpreta o mundo. O mundo inteiro se converte no cenário onde se cumpre a promessa publicitária de uma vida boa. O mundo nos sorri. Oferece-se a nós. E como imaginamos que todos os lugares se oferecem a nós, todos os lugares vem a ser mais ou menos o mesmo (BERGER, 2012, p. 164-165).

Um pouco desta perspectiva analisada por Berger talvez possa ser observada nos cartazes aqui contemplados. No entanto, desfazendo as sombras da ditadura, recuperando a história como campo de possibilidades, diferentes sujeitos, a maioria deles coletivos, criam que o mundo voltava a sorrir no ocaso do regime autoritário. A interpretação não unívoca do mundo permitia pensar - nas fissuras da publicidade - que era preciso propagandear sobre a sociedade

4 "A restrição do sentido da palavra [propaganda] ao campo comercial, a nada mais do que a preconização astuta de mercadorias, corresponde a um estreitamento do século XIX, e principalmente, do XX..." e contraria a "gama de significados similarmente vasta ao que se chama hoje "ação comunicativa", que provém da Idade Média (TÜRCKE, 2010, p. 24). A propaganda anunciava uma novidade, como é o caso do evangelho. Ela pretendia abordar um tema, um assunto, um problema, convencer sobre alguma coisa pelo poder da argumentação. Assim, parto do entendimento de que a propaganda é uma das grandes armas da política, seja em regimes autoritários ou totalitários, seja em regimes democráticos, e os cartazes aqui explorados o exemplificam. A restrição a que se refere Türcke permitiu o surgimento do império da publicidade, uma vez que a propaganda teria se reduzido quase totalmente ao mundo do comércio e do consumo. 
que se pretendia abandonar, e aquela que era preciso desejar para, quem sabe, um dia poder ser realizada. No mínimo, sobre os anos 1980, podemos dizer que a coragem latente de muitos que estiveram estarrecidos com a experiência da ditadura finalmente pôde ganhar o espaço público através de uma presença vigorosa da propaganda que advogava outro mundo possível. Isso certamente é um paradoxo em relação às considerações de Berger, mas podemos captar a propaganda, em termos políticos, em sua face contra-hegemônica.

Não é demais lembrar que a propaganda tem sido utilizada ao longo da história também como possibilidade de educação, dos grupos subalternos em especial. Desde as campanhas de anarquistas e socialistas (HARDMAN, 2002), passando pelo integralismo e a ação católica, a propaganda que apela para as imagens busca sensibilizar aqueles que ainda não estão plenamente convencidos de uma "causa", ou reafirmar o ânimo daqueles que por ela militam e a ela disseminam.

Por exemplo, os diferentes bandos da Guerra Civil espanhola produziram uma espantosa quantidade de peças de propaganda, tendo justamente os carteles como um dos seus meios mais eficazes, como bem mostram Sanz et al. (2010). Esse tipo de comunicação permite articular arte e propaganda - no caso espanhol, propaganda em tempos de guerra - uma vez que o seu processo de produção permitia a difusão de ideias conservadoras ou revolucionárias a partir da sensibilidade de artistas de diversa qualidade, sensibilidade esta registrada ora de maneira refinada, ora de maneira rude, conforme também a disponibilidade de recursos daqueles que encomendavam esse tipo de propaganda. $\mathrm{Na}$ Espanha, autores como Picasso e Miró produziram verdadeiras obras de arte que tinham o fim precípuo de fomentar a tomada de consciência da população em relação à Guerra Civil.

Analisando a história política recente do Brasil, conhecemos o fantástico trabalho de Ricardo Carvalho, Vladimir Saccheta e José Luiza Del Roio (2012), que contribui para a atualização da memória sobre a ditadura brasileira, analisando um conjunto de quase 250 cartazes, muitos produzidos no exterior, contrários aos militares brasileiros e às suas políticas.

Tanto o livro espanhol quanto o brasileiro, ambos esteticamente belíssimos e tratando de dois momentos de grande violência institucional que produziriam dois regimes claramente autoritários e antidemocráticos, ainda que apresentem textos que ajudam o leitor a compreender um momento específico da história dos dois países, têm na imagem dos cartazes sua principal força, na medida em que a cultura da imagem tende a produzir um efeito imediato de sensibilização daqueles que por ela são afetados, em muitos casos sem a mediação da palavra. O cartaz é cor, é textura, em muitos casos denota movimento. Sua plasticidade supera em muito a fixidez do texto político monocórdio e a linguagem progra- 
mática - na maioria das vezes, vazia - da militância profissional. O cartaz, no qual o texto é ora complemento, ora índice, deve apreender pelos sentidos, deve seduzir, deve encantar. Minha hipótese é que o seu momento expressivo, que poderia até mesmo ser ignorado, produzia um impacto que, em alguma medida, "educava", uma vez que ao primeiro olhar um conjunto de sensações era mobilizado e o observador era afetado ${ }^{5}$. Clandestinamente a mensagem imagética combina convencimento e encantamento, daí o esmero com o qual muitas peças de propaganda foram produzidas, até mesmo, e provavelmente muito mais, pelos regimes autoritários. Mas aqui os cartazes dizem da possibilidade histórica. E dizem com cores, ora com requinte, ora com simplicidade, que novamente se poderia construir um país. Tornaram-se documentos...

O colecionador que acumulou tantos registros imagéticos, inebriado tanto pela sua plasticidade quanto pelo conteúdo da mensagem que pretendia convencer, ainda que inconscientemente, talvez o tenha feito movido por aquela dialética memória/esquecimento, captada por Walter Benjamin (1994b; 2005). Não é demais recordar que este autor estava atento à fluidez e a precariedade da informação em detrimento da experiência e da necessidade do historiador ser um crítico do presente. Nesse caso, mesmo os cartazes sendo oriundos do universo da publicidade, a sua composição reservava lugar para a criação artística, sendo o colecionador o responsável involuntário pela sua validez como documento histórico, uma vez que nenhuma "obra" do passado pode ser considerada acabada. Ela não se encerra em si, mas diz de trabalho, sacrifício e labor, e continua a afetar e existir na sua produção, recepção e transmissão. No mesmo sentido o passado não está morto, ainda que possa aparecer encoberto ao presente. O colecionador, como o historiador, se vê diante de uma relação "viva", na qual estilhaços de embates pretéritos continuam a atualizar e a transmitir a possibilidade histórica e a esperança.

Se a arte é trabalho e também é do domínio da estética a inversão do mundo e seu descortinamento, aquele que coleciona permite que um registro tão fugidio de tempos passados assuma a condição de vestígios de uma história ainda não contada, ou apenas parcialmente narrada, aberta, na qual agentes individuais e

5 Talvez seja impossível dimensionar o alcance da recepção de um tipo de mensagem midiática caracterizada pela sua própria fungibilidade, como é o caso do cartaz. Logo, seguindo a chave analítica de John Berger, apenas é possível supor como as pessoas decodificam determinada imagem, uma vez que tenham sido afetadas por ela. Mas bem sabemos que a ilustração, a gravura, o desenho são recursos técnicos poderosos para produzir mensagens, inclusive, para populações não alfabetizadas (THOMPSON, 1987). Essas mensagens podem produzir a manutenção do status quo, porém, podem representar possibilidades de questionamento de suas bases. Em um caso ou outro é que pressuponho tratar-se de um tipo de educação, que vimos chamando dos sentidos e das sensibilidades. 
coletivos produziram sua própria história. Nada era óbvio na fruição daquilo que se converteria em documento histórico.

Al coleccionador, lo decisivo es que el objeto sea liberado de todas sus funciones originales para entrar en la más íntima relación pensable com sus semejantes. Esta relación es diametralmente opuesta a la utilidad, y figura bajo la estraña categoria de la compleción. Que es esta compleción? Es el grandioso intento de superar la completa irracionalidad de su mera presencia integrandolo em un nuevo sistema histórico creado particularmente: la colección (BENJAMIN, 2005, p. 223).

Pois bem, não seria também a propaganda - política, cultural - sobretudo em um tempo no qual a vida pública poderia ser restaurada, outra possibilidade de intercambiar experiências? O colecionador inconsciente, movido por um impulso de acúmulo, é tocado por uma narrativa que atualiza planos e lutas passadas. Logo, o acúmulo como fim nele mesmo se mostra portador de uma potência de produção da memória que grita que é preciso seguir resistindo e enfrentando as velhas batalhas, que se atualizam em cada traço, cada cor, cada mancha, cada impressão de homens e mulheres em uma folha inerte de papel que é tornada mensagem de esperança. O colecionador não sabia disso até que aqueles vestígios permitissem explodir na consciência a necessidade de lutar contra o esquecimento. Também não percebeu imediatamente que aquele tipo de produção continha elementos reatualizados de uma longa história de grupos sociais em busca do seu lugar na distribuição desigual de poder daquela sociedade. Ao perceber, voltou a Benjamin: "Quem não é capaz de tomar partido tem que calar-se" (BENJAMIN, 1995, p. 32).

Assim, nos limites aqui permitidos, pretendo explorar algumas poucas imagens selecionadas de uma coleção de aproximadamente 800 cartazes $^{6}$. Deste universo foi feita uma seleção inicial que deu origem a uma série de 89 documentos, estes organizados em 5 subséries: 1. Fumar é...; 2. Movimentos

6 Produzi essa coleção ao longo de mais ou menos 15 anos, entre o final da década de 1970 e o começo da década de 1990. Nos dois últimos anos parte desse material foi tratado, para fins de exposição, com recursos de diferentes agências, e passará a fazer parte do acervo da UFMG. A falta de datação precisa de cada documento, muito difícil nesse caso, não prejudica a constatação de que eles dão visibilidade a um conjunto de lutas daquele período, que é interesse maior do trabalho. A seleção dos cartazes se deu com a imprescindível colaboração e sensibilidade de Luisa Cecília Belotti Oscar (PIBIC/CNPq), e da professora Katya Braghini. As fotos dos cartazes foram realizadas por Tiago Osório de Nazaré. Agradeço aos três pela parceria. 
Sociais; 3. Políticos; 4. América Latina; 5. Arte. A série Fumar é..., que aqui não será tratada, produzida pelo governo no final da década de 1980, acirrava a luta contra o fumo com um tom já ancorado no politicamente correto que se alastraria pela sociedade brasileira nas décadas seguintes. A autoria dos cartazes é de Ziraldo. Visualmente bonitos, extremamente coloridos, com mensagem agressiva - Fumar é brega!; Fumar é cafona!; Fumar é patético!; Fumar é de mau gosto!; Fumar é careta!, a série foge dos propósitos desse trabalho justamente porque dá vazão a uma campanha capitaneada pelo estado brasileiro e pela Organização Mundial de Saúde, que ridicularizava um hábito propalando o mito da saúde perfeita, que viria a desembocar na ideologia do estilo de vida ativo. Entendo que pouco tinha a ver com a mobilização dos movimentos sociais... Já nas demais séries, é possível observar vestígios de uma esperançada reorganização da sociedade civil. No conjunto das peças é possível encontrar obras maravilhosas de artistas como Carlos Vergara e Elifas Andreatto, que marcaram a cultura brasileira, entre outras coisas, pelo fascínio da sua arte das capas dos antigos long plays, embora essa seja apenas uma faceta do seu trabalho.

Excetuando a série Fumar é..., as peças são emblemáticas do estado de ânimo de entidades e movimentos sociais no Brasil, que pareciam acreditar que, finda a ditadura, outro país poderia ser construído a partir da participação de todos. Alguns cartazes são intensos, alegres e profundos, como aquele no qual a mulher amamenta seu filho em uma manifestação popular nicaraguense. ${ }^{7}$

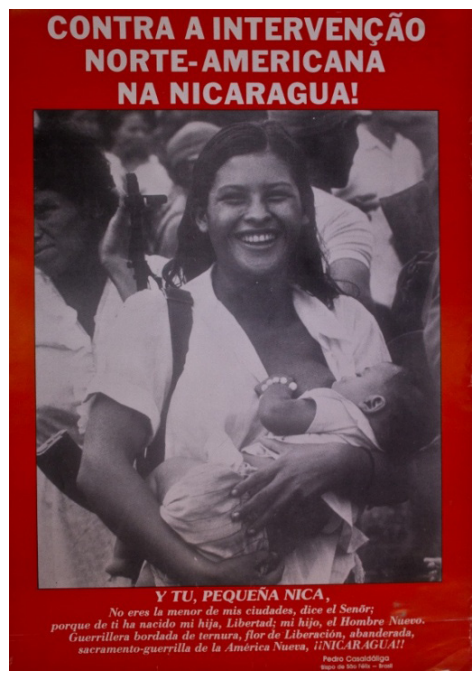

7 As imagens dos cartazes falam por elas mesmas e conformam parte da trama no seu encontro com o texto. Logo, elas não têm título ou numeração, pois não são meras ilustrações para o texto, mas parte da narrativa. Agradeço ao editor pelo respeito à minha escolha. 
Seu enquadramento vermelho denota a força de um povo, exemplo para a América Latina, que por décadas combateu o imperialismo. Ao mesmo tempo alimentava a esperança, aconchegada no colo e expedita no sorriso de quem amamenta em movimento, pois representava uma tomada de consciência de determinados grupos sociais em relação à necessária integração do país na América Latina, recuperando sonhos acalentados por intelectuais como Manoel Bonfim (2000) e Rocha Pombo (1900) no começo do século XX. Não é casual que o texto em sua base seja de Pedro Casaldáliga e esteja em castelhano. O país parecia atualizar um entendimento já compartilhado em outros tempos, de que não só mazelas como a tortura, o exílio, a Operação Condor nos irmanavam, mas a narrativa histórica dos povos latino-americanos seria uma alternativa às interpretações emanadas dos Estados Unidos e da Europa sobre o devir da região, sobretudo em relação àquilo que se relacionava ao intervencionismo estadunidense.

Outros cartazes são singelos, muitos produzidos em papel jornal, como a campanha pública da União Nacional dos Estudantes - UNE, contra Paulo Salim Maluf, um quase presidente da república com forte lastro entre o empresariado e que despertava sentimentos ambíguos na caserna. Mesmo assim a força das suas imagens não deixa dúvidas quanto ao seu significado para uma cultura que busca sorver ares menos tóxicos.

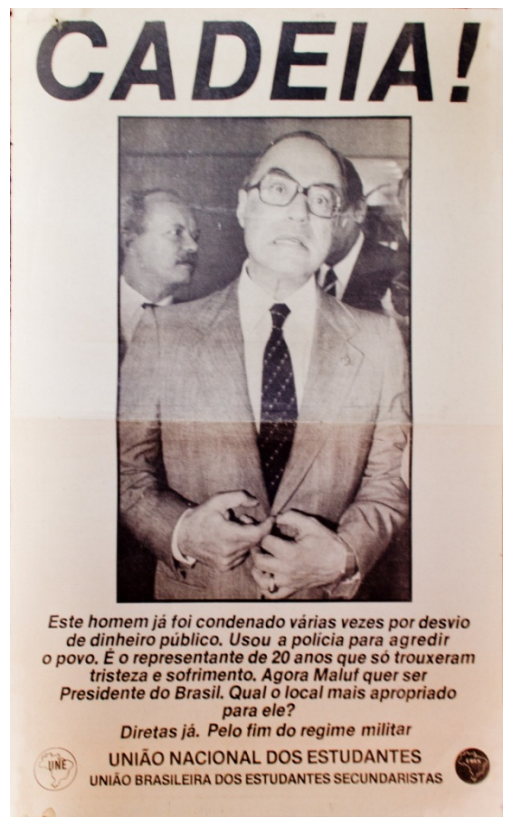


Temas sufocados pela ditadura, como a luta pela terra, expressos no clamor pela reforma agrária e na reivindicação dos direitos dos povos indígenas, a redefinição do lugar e do papel das mulheres na sociedade, a recuperação da utopia de congraçamento e integração do Brasil com os coirmãos da América Latina, a reivindicação de uma política cultural inclusiva e democrática, a preservação ambiental, o combate à corrupção, são alguns dos que ganharam os muros e as paredes das cidades brasileiras em um verdadeiro calidoscópio que tentava disseminar a ideia de que se tratava, ao longo da década de 1980, de um novo tempo.

As três ou quatro décadas que se seguiram mostram que muitas das lutas encetadas contra os militares no poder eram, na verdade, apenas parte de outra, maior, que precisamos enfrentar cotidianamente, uma vez que a clivagem social, política e econômica de uma sociedade como a brasileira tem demonstrado que a violência disseminada e sustentada pela caserna é, de fato, o modus operandi dos grupos dominantes neste país, tão zelosos das suas sinecuras, a ponto de muitos dos enfrentamentos que ganharam outras cores nos anos pós-ditadura, ainda hoje marcarem o cotidiano de diferentes grupos sociais, no Brasil.

Não deixa de ser um problema observar que, a despeito das campanhas como a da União Nacional dos Estudantes - UNE, e do peso que o tema da educação e da juventude ganhou na Assembleia Nacional Constituinte de 1987,

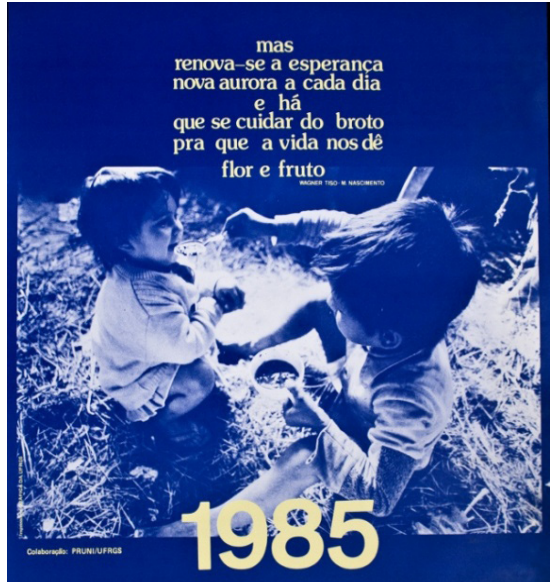

ANO INTERNACIONAL DA JUVENTUDE

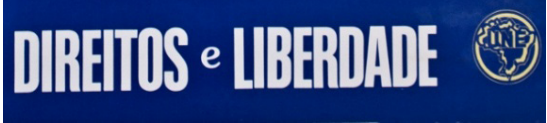

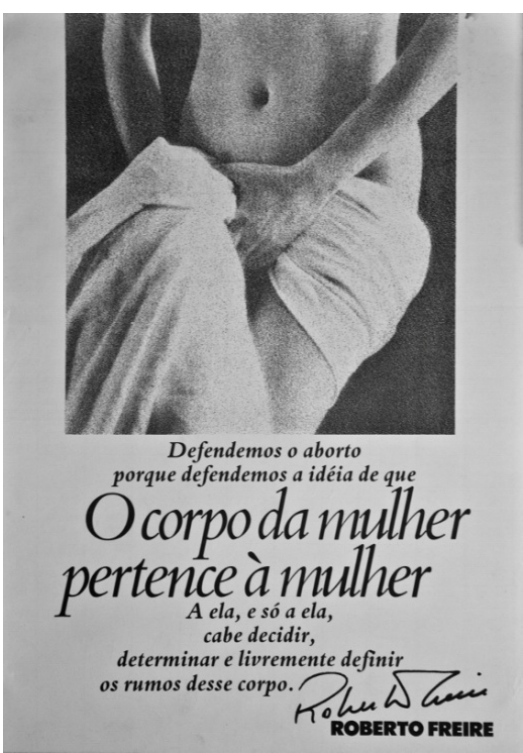


em 2010 o censo do IBGE mostrasse que estamos longe de ter a educação básica universalizada; um contingente absurdo de jovens - 20\% na faixa dos 15 aos 29 anos - não estuda ou trabalha; a escola pública, o professor e sua carreira são tratados como estorvo das políticas econômicas. A esperança que parecia se renovar naquele 1985, Ano Internacional da Juventude pela UNESCO, não encontrou no Estado ou na sociedade civil forças capazes de fazer valer a máxima de que a vida renovada nos daria "flor e fruto", no enquadramento azul que remete à harmonia, à serenidade, ao infinito. Não só parte da sociedade brasileira continua a lutar pelo direito a uma escola pública de qualidade para os jovens, como precisa lembrar que o maior contingente de jovens entre 15 e 29 sem trabalho ou escola é de mulheres (quase $71 \%$ ). O indicador oficial apenas atesta a violência multifacetada que se atualiza e afeta as mulheres neste país, sobretudo as mais pobres (e, provavelmente, negras), ainda que no período pós-ditadura os direitos da mulher fossem moeda corrente nos mais diversos discursos políticos.

Mas essa violência também se atualiza na luta pela terra e na falta de escrúpulos dos grandes proprietários e dos barões do agronegócio, talvez um dos grupos políticos mais organizados do país, com forte capacidade de orientar a formulação de políticas econômicas e sociais. Recentemente uma jovem líder ruralista do Mato Grosso do Sul, branca e rica, diante da iminência de conflitos com os índios da região - conflito que já produzira a morte do índio terena Oziel Gabriel, em junho de 2013 -, argumentava na grande mídia que os índios "precisavam entender" que a sua família tinha documentos de posse daquelas terras desde o séc. XIX! Para os ruralistas caberia ao Estado garantir a posse das terras e a segurança dos índios, uma vez que, sem a sua presença na repressão aos índios, o agronegócio se mobilizaria, inclusive com a organização de milícias, para enfrentá-los ${ }^{8}$. Em nenhum momento se considera o direito imemorial de uma "minoria" frente ao apetite voraz da expansão do capitalismo agropecuário.

Esses dois exemplos de atualização da memória dos excluídos que, a despeito de terem ganhado as ruas em campanhas de forte impacto emocional,

8 “Em 2010, o Ministério da Justiça delimitou a Terra Indígena e determinou que os índios terena têm direito à posse e ao usufruto exclusivo da área. No entanto, fazendeiros se recusam a sair e têm conseguido travar a conclusão do processo na Justiça. As negociações para acabar com o impasse empacam num ponto: como indenizar os fazendeiros pelas terras. A Constituição determina que não índios a serem expulsos de áreas indígenas só podem ser indenizados por benfeitorias, como casas. Acontece que muitos dos fazendeiros detêm os títulos dessas áreas (emitidos pelo Estado há décadas) e querem compensação por todo o terreno a ser desapropriado". Matéria de João Fellet para a BBC Brasil em 29 de novembro de 2013. A pergunta que os anos 80 permitem formular é: qual a legitimidade do Estado que emitira tais títulos? Disponível em: $<\mathrm{http} / /$ www.bbc.co.uk/portuguese/ noticias/2013/11/131129_forca_nacional_sidrolandia_ms_mm.shtml >. Acesso em: 23/02/2014. 

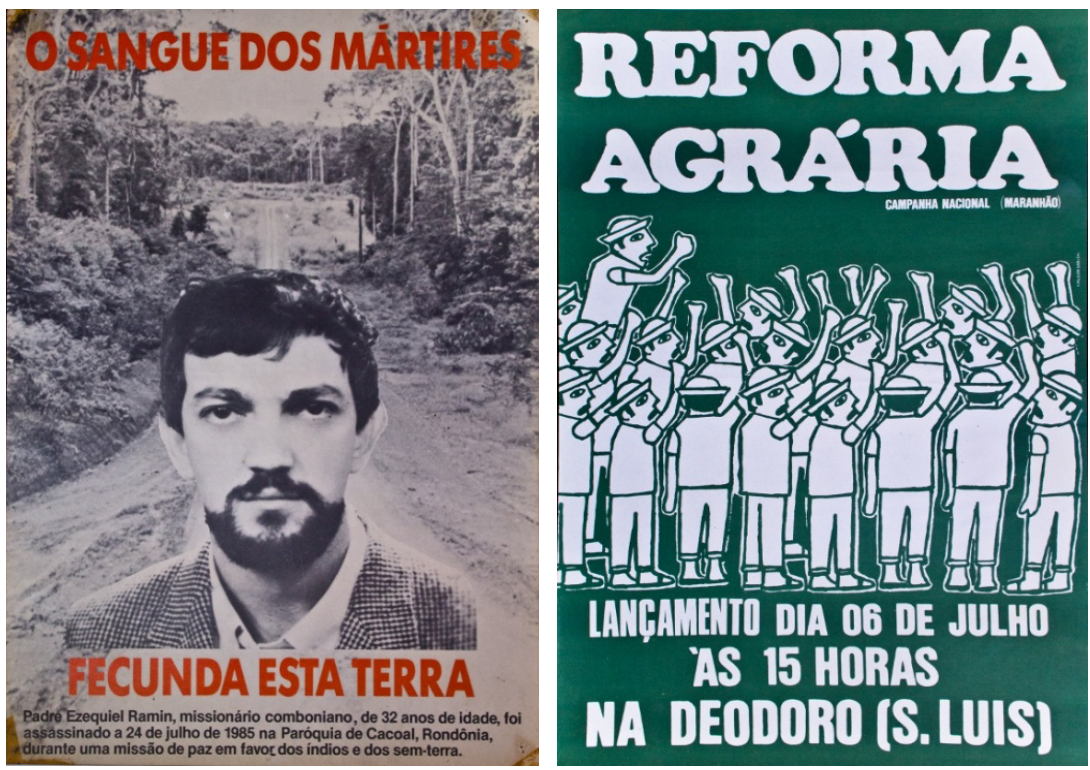

mostram como muito do que se proclamou nos discursos dos anos 1980 parece não ter sido suficiente para pautar na agenda política brasileira o combate a formas centenárias de violência e exclusão, expresso sobretudo na atenção dada às minorias em nosso país.

Mas parte da sociedade, assim como hoje, cumpria o papel de esclarecer pelo texto, pela imagem, pela denúncia, pela beleza, pela mobilização, a possibilidade de construir outro país, no qual aquela violência que mata, ou aquela que mutila e oprime, fosse combatida como uma chaga que nos impede de realizar plenamente a tão almejada, propalada e sempre negligenciada modernização social e cultural, a menos que a consideremos na sua face autoritária e conservadora. Para isso estava claro, pelo menos para algumas parcelas da população, que o combate à corrupção talvez significasse enfrentar uma das formas mais arraigadas de violência que produziu um dos países mais injustos e desiguais do mundo, como mostra a campanha da UNE em relação às eleições para presidente, em 1985. Aquele homem, retrato acabado de muitos políticos brasileiros, foi novamente sentenciado há poucos meses, no ano de $2013^{9}$. Tal-

9 Paulo Maluf está envolvido em processos judiciais desde o ano de 1981. Veja os processos judiciais que envolvem o deputado Paulo Maluf. Disponível em: $<$ http://www.estadao.com.br/ noticias/nacional,veja-os-processos-judiciais-que-envolvem-o-deputado-paulo-maluf,1093390,0. htm> Acesso em: 05/11/2013. 

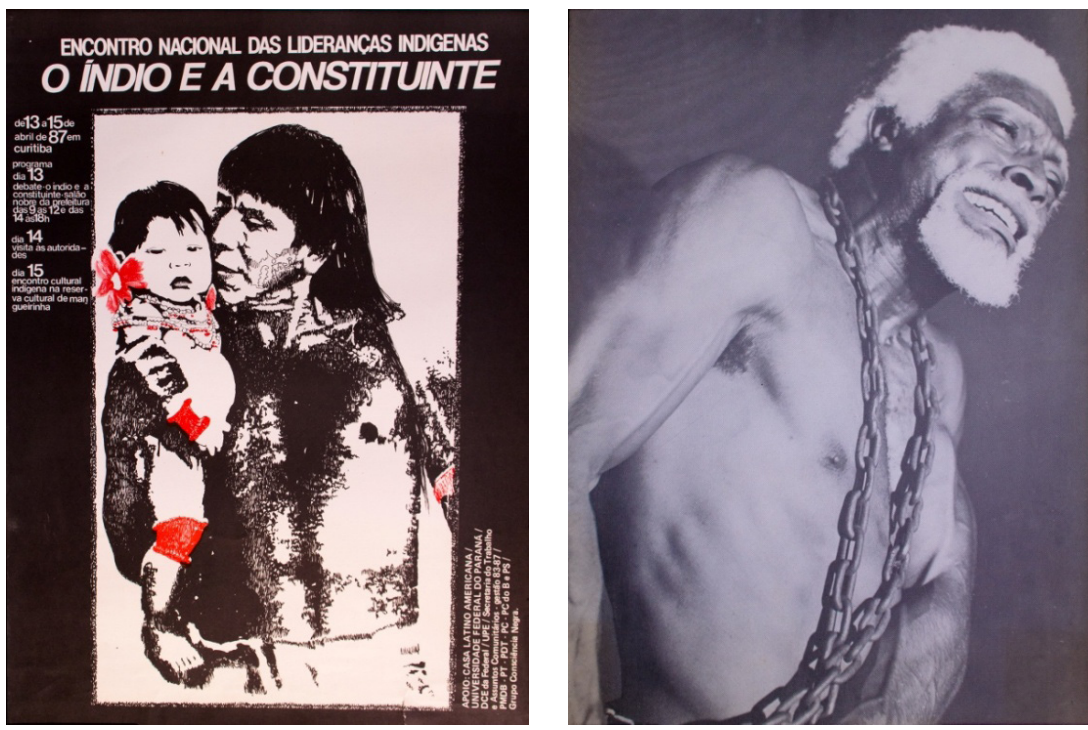

vez os recentes episódios nos quais políticos condenados por corrupção foram encarcerados sejam um alento para aqueles que há muito combatem contra a disseminação da corrupção e da impunidade que a acompanha. Em um país que cultuou e continua a cultuar o "jeitinho" como algo que é parte da sua identidade, a perpetuação de práticas de compadrio que embaralham o público e o privado, a política e os interesses corporativos, aquela década de esperança parecia produzir uma mensagem de que estaríamos atentos contra a perpetuação de formas ilegítimas de exercício do poder, mesmo que o aparato legal às vezes continuasse - e continue - a tentar legitimar a desfaçatez.

Não conquistamos o mundo que a década perdida prometeu. Aquela intensa mobilização política pela propaganda talvez tenha esbarrado nas suas próprias contradições, como provoca a pensar John Berger.

O abismo entre o que a publicidade oferece realmente e o futuro que promete corresponde ao abismo existente entre o que o expectadorcomprador crê ser e o que gostaria de ser. Os dois abismos se convertem em um: no lugar de salvá-lo com atuação ou a experiência vivida, tentase preenchê-lo com um fascinante sonhar acordado. As condições de trabalho vêm às vezes completar esse processo (BERGER, 2000, p. 163). 
Claro que Berger se refere à propaganda que vende "coisas" - carros, fitness, arte - e a sua crítica não recai diretamente sobre suas possibilidades para o universo da política, mesmo sendo crítico ferino de "políticas culturais". Afinal, quem faz a "cultura"? Mas, se a propaganda vende sonhos, parece que os sonhos acalentados por aqueles cartazes dos anos 1980 representavam, no mínimo, um regozijo: a ditadura dava seus estertores, mesmo que muitos deles continuem assombrando a sociedade brasileira hoje.

Cambaleantes, andamos pela senda do desemprego estrutural, pelo alijamento da participação popular, pela exclusão social, cultural, econômica, pelo colapso da representação política. Mas se o fazemos é porque muito do que foi sonhado, desejado, divulgado, propagandeado, foi também sabotado pelos arranjos violentos de um poder que não cansa de se atualizar, do qual a ditadura civil-militar brasileira foi uma das expressões. Isso nos provoca a (re)elaborar o passado tanto no que ele significou de violência, abandono e terror, mas também de esperança, ação e resistência. Se havia aqueles que, como assinalou Theodor Adorno (1995), não queriam ouvir, pois obedeciam à “...conformidade com uma vigorosa tendência histórica” (ADORNO, 1995, p. 32), também é preciso reconhecer que a atualização de lutas expressas nos cartazes da década de 1980 representou o índice mais evidente de que parte da sociedade brasileira se negava a esquecer, ao abandono da memória. "Quando a humanidade se aliena da memória, esgotando-se sem fôlego na adaptação ao existente, nisto reflete-se uma lei objetiva de desenvolvimento" (ADORNO, 1995, p. 33).

Talvez possamos sustentar que, na mesma perspectiva, nos anos finais daquela década, Edward Thompson preparava seu Costumes em Comum. Naquela obra, em uma alentada introdução, ele imaginava que batalhas perdidas há duzentos anos pela população mais pobre na Europa, poderiam ser ganhas no hemisfério sul do globo, aquele que em linguagem bastante comum ao longo daqueles anos concentrava o terceiro mundo. Mundo este que, como asseveram Pineau et al. (2006), independentemente do tamanho e do alcance da violência que sobre ele se abate, não deixa de comportar (às vezes tímidas) formas de resistência, que denotam a agência humana na história. Creio que um dos maiores efeitos duradouros da ditadura entre nós tenha sido a perda de perspectiva de uma justiça plena, aberta e irrestrita, que acabou com a nossa vontade de desenvolver uma ética que servisse a todos, não apenas a grupos isolados capazes de auto-organização. Por outro lado, o parcelamento das lutas que produziram agendas pautadas e localizadas conseguiu inserir nos currículos escolares outro tipo de conteúdo, que valorizou a cultura afro-brasileira; que as "diversidades" se tornassem pontos de pauta importantes na agenda política da sociedade brasileira; essa sociedade produziu a Lei das Cotas para ingresso nas universidades públicas, a lei Maria da Penha; a lei contra a discriminação 
com prisão inafiançável, entre tantas outras conquistas que não são pequenas em um país onde aos "de baixo" foi definido que sempre deverão permanecer embaixo. Não parece pouco se pensarmos que até hoje há quem julgue esse movimento social ilegítimo. As fontes estão aí para mostrar que muito se fez na década de 1980 para que este país fosse pelo menos um pouco melhor. Mas poderia haver alguma mudança estrutural na sociedade brasileira, que investisse no projeto de uma sociedade melhor para todos, decididamente? Recuperando a ideia central de Thompson, provavelmente essa luta foi perdida, também, no Brasil e na América Latina, e as suas ditaduras muito contribuíram para que isso fosse um fato histórico.

Talvez, na companhia da turma do Henfil, possamos atualizar a pergunta da sua Graúna: "Tão vendo alguma esperança?".

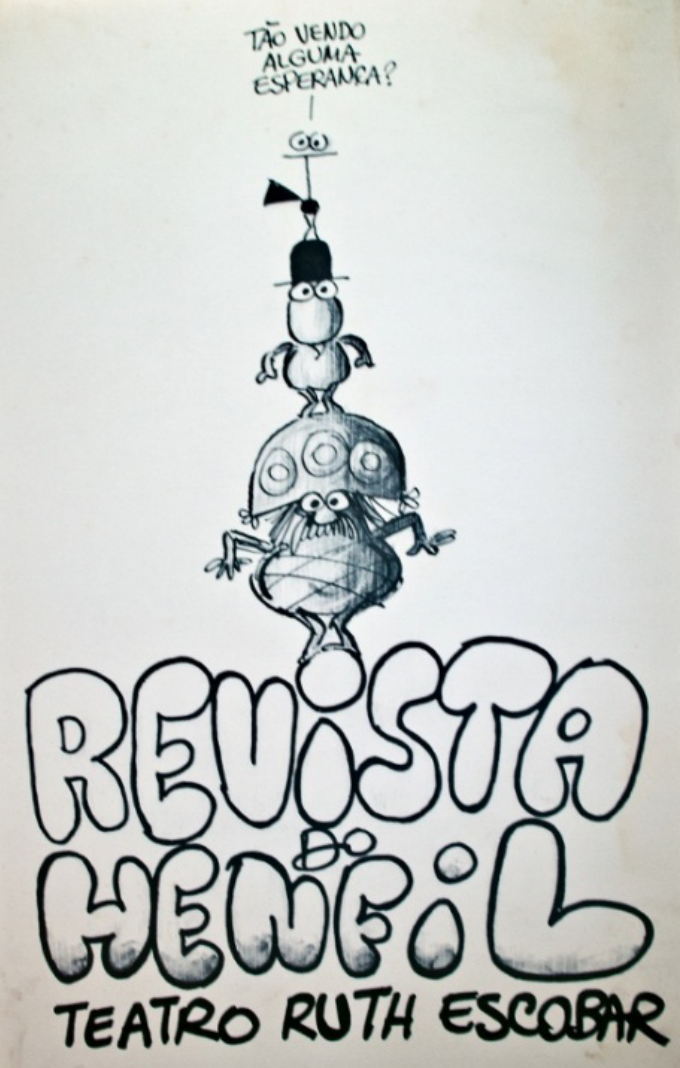




\section{REFERÊNCIAS}

ADORNO, T. W. O que significa elaborar o passado. In: Educação e Emancipação. São Paulo: Paz e Terra, 1995.

BENJAMIN, W. Magia e técnica, arte e política. São Paulo: Brasiliense, 1994a. 1994b. . Proibido colar cartazes! In: . Rua de mão única. São Paulo: Brasiliense,

. Libro de los pasajes. Madrid: Akal, 2005.

BERGER, J. Modos de ver. Barcelona: Editorial Gustavo Gili, 2012.

BONFIM, M. A América Latina. In: SANTIAGO, S. (Org.). Intérpretes do Brasil. Rio de Janeiro: Nova Aguilar, 2000. v. 1.

CARVALHO, R. et al. (Orgs.). Os cartazes desta história. São Paulo: Escrituras, 2012.

FELLET, João. Governo enviará Força Nacional a MS para impedir conflitos por terras. BBC Brasil, 29 nov. 2013. Disponível em: <http://www.bbc.co.uk/portuguese/noticias/2013/11/131129_forca_nacional_sidrolandia_ms_mm.shtml $>$. Acesso em: 30/11/2013.

HARDMAN, F. F. Nem pátria, nem patrão!. São Paulo: UNESP, 2002.

O ESTADO DE SÃO PAULO. Veja os processos judiciais que envolvem o deputado Paulo Maluf. Estadão.com.br, 5 nov. 2013. Disponível em: <http://www.estadao.com. br/noticias/nacional,veja-os-processos-judiciais-que-envolvem-o-deputado-paulo-maluf,1093390,0.htm>. Acesso em: 25/11/2013.

PINEAU, P. et al. El principio del fin. Políticas y memórias de la educación em la última dictadura militar (1976-1983). Buenos Aires: COLIHUE, 2006.

ROCHA POMBO, J. F. História da América. 1. ed. Rio de Janeiro: Laemmert \& C. Editores, 1900.

SANZ, J. de A. et al. (Orgs.). Carteles de la Guerra Civil Española. Madrid: Susaeta Ediciones, 2010.

TAIGUARA. LP Viagem. Odeon. 1970.

THOMPSON, E. A formação da classe operária inglesa. São Paulo: Paz e Terra, 1987. TÜRCKE, Christoph. Sociedade excitada: filosofia da sensação. Campinas: Unicamp, 2010. WILLIAMS, R. Política do modernismo. São Paulo: UNESP, 2011a. . Cultura e materialismo. São Paulo: UNESP, 2011 b.

Texto recebido em 12 de dezembro de 2013. Texto aprovado em 04 de janeiro de 2014. 